\title{
Evaluation of Salivary Secretor Status of Blood Group Antigens in Patients with Oral Lichen Planus
}

\author{
Sedigheh Bakhtiari ${ }^{a}$ Parviz Toosi $^{\mathrm{b}}$ Fariba Dolati ${ }^{\mathrm{a}}$ Mahin Bakhshi ${ }^{\mathrm{a}}$ \\ ${ }^{a}$ Department of Oral Medicine, Dental Faculty, and ${ }^{b}$ Department of Dermatology, Shahid Beheshti University of \\ Medical Sciences, Tehran, Iran
}

\section{Key Words}

ABO blood group $\cdot$ Secretor status $\cdot$ Oral lichen planus

\begin{abstract}
Objective: To investigate the relationship between secretion or nonsecretion of blood group antigens into the saliva and oral lichen planus (OLP). Subjects and Methods: In this study, 30 patients (women: 22, men: 8) with OLP were examined as the case group and 30 subjects without OLP matched for age and gender as the control group. Diagnosis of OLP was confirmed by clinical and histopathological examinations according to WHO criteria. The control group was randomly selected from healthy individuals without pathological oral changes seeking dental treatment. In both groups, blood group type was determined by hemagglutination, and unstimulated saliva was collected using the Navazesh technique. Establishment of salivary secretor status was carried out using the Wiener agglutination test. The data were analyzed using a $x^{2}$ test, Fisher's exact test, and logistic regression. Results: The patients with OLP (cases), including 22 (36.7\%) women and $8(13.3 \%)$ men with a mean age of $51 \pm$ 14.16 years, were compared with healthy subjects (controls), comprised of $25(41.7 \%)$ women and $5(8.3 \%)$ men with a mean age of $50.7 \pm 13.56$ years. A large majority of the people examined in both groups were secretors of blood group
\end{abstract}

\begin{tabular}{ll}
\hline KARGER & $\begin{array}{l}\text { ( } 2015 \text { S. Karger AG, Basel } \\
1011-7571 / 15 / 0253-0266 \$ 39.50 / 0\end{array}$ \\
E-Mail karger@karger.com & $\begin{array}{l}\text { This is an Open Access article licensed under the terms of the } \\
\text { www.karger.com/mpp }\end{array}$ \\
$\begin{array}{l}\text { Creative Commons Attribution-NonCommercial 3.0 Un- } \\
\text { ported license (CC BY-NC) (www.karger.com/OA-license), } \\
\text { applicable to the online version of the article only. Distribu- } \\
\text { tion permitted for non-commercial purposes only. }\end{array}$
\end{tabular}

A. On the other hand, most OLP patients were blood group B. In the case group, 25 subjects (84.4\%) were secretors and $5(16.6 \%)$ were nonsecretors. In the control group, 24 subjects $(80.0 \%)$ were secretors and $6(20.0 \%)$ were nonsecretors. There was no significant difference between the case and control groups for secretor status $(p=0.73)$. Conclusion: The present study did not indicate a significant difference in salivary secretor status between OLP patients compared to controls.

(c) 2015 S. Karger AG, Basel

\section{Introduction}

The ABO blood group antigens are found on red blood cells, as well as in saliva and in all human body tissue [1]. Secretors secrete $\mathrm{ABO}$ blood group antigens into body fluids such as saliva, sweat, digestive secretions, breast milk, and tears. Individuals who do not secrete blood group antigens into the body fluids are called nonsecretors [2, 3]. In 1930, the ability to recognize blood group antigens secreted in the saliva allowed the categorization of individuals as secretors or nonsecretors [1, 4]. Approximately 15\% of the general population are nonsecretors [1].

The secretion of antigens into the saliva and mucus can increase protection against bacterial fimbriae lectins. 
Previous studies have indicated that nonsecretors are more prone to certain diseases such as autoimmune diseases [5], peptic ulcers [6], vaginal candidiasis [7], and oral changes like oral submucous fibrosis [8], dental caries $[9,10]$, and periodontal disease [11].

Thom et al. [12] reported that precancerous oral lesions and oral cancer showed higher association incidence with nonsecretors. However Shin et al. [13] could not establish an association between oral candida with secretor status or ABO blood groups. Vidas et al. [4] reported that nonsecretor status was not a risk factor for precancerous oral lesions and found a higher percentage of oral disease in nonsecretors; they also noted that the occurrence of epithelial dysplasia was more frequent in nonsecretors.

Information about the influence of secretor status on oral lichen planus (OLP) is not readily available in the Iranian population. Therefore, the aim of the present study was to investigate the relationship between salivary secretor status and OLP as predisposing factors for this lesion.

\section{Subjects and Methods}

\section{Source of Participants}

This study was conducted at the Department of Oral Medicine, Shahid Beheshti University of Medical Sciences, Tehran, Iran. Thirty patients (females: 25, males: 5) were randomly selected for the control group from the patients without pathological oral changes seeking dental treatment. The case group comprised 30 patients (females: 22, males: 8) with OLP, which was confirmed clinically (reticular and common form with Wickham striae) and by histopathological assessment in cases where there was difficulty in making a definite diagnosis of lesions. Histopathologic confirmation was carried out according to WHO criteria [14].

The oral examination was performed by two expert clinicians; an oral medicine specialist (S.B.) and a dermatologist (P.T.). The clinical examinations were done using two plain mouth mirrors under artificial light. An oral pathology specialist confirmed the biopsied lesions.

The Medical Ethics Committee of Shahid Beheshti University of Medical Sciences approved the study. Written informed consent was obtained from all participants.

\section{Laboratory Procedure}

Blood samples were taken from all participants by capillary puncture with a lancet. Blood type was determined using a conventional hemagglutination test. Anti- $\mathrm{A}$, anti- $\mathrm{B}$, and anti- $\mathrm{H}$ reagents were used in red blood cell determination of the ABO blood group. Next, $1 \mathrm{ml}$ of unstimulated saliva was obtained from each subject using the Navazesh method [15]. Saliva was transferred into a sterile test tube that was then sealed with nonabsorbent gauze and placed in a boiling water bath for $10 \mathrm{~min}$. It was then centrifuged at $1,700 \mathrm{rpm}$ for $10 \mathrm{~min}$ and the supernatant was sep- arated by decantation. The upper layer of centrifuged saliva was used to identify secretors and nonsecretors.

Analysis of secretor status was carried out by Wiener agglutination testing [4]. The test serum and the saliva were diluted with a saline solution at a ratio of 1:10. The following antiserum was poured into test tubes numbered I-IV: test tube I = 1 drop of saliva +1 drop of anti-B serum; test tube II = 1 drop of saliva +1 drop of anti-A serum; test tube III = 1 drop of saline solution +1 drop of anti-B serum, and test tube IV = 1 drop of saline solution +1 drop of anti-A serum.

After $10 \mathrm{~min}$ at room temperature $\left(20^{\circ} \mathrm{C}\right), 1$ drop each of $2-3 \%$ $\mathrm{A}_{2}$ erythrocyte solution in saline solution was added to test tubes II and IV. One drop each of 2-3\% B-erythrocyte solution in saline solution was added to test tubes I and III. All of the test tubes were shook and kept at room temperature. The results were recorded after $1 \mathrm{~h}$.

\section{Determining Secretors and Nonsecretors}

The test was based on the ability of saliva to inhibit the agglutination reaction of blood groups, such as antibody A without Ag A in the saliva $\rightarrow$ no agglutination (secretor), but mixture of antibody $\mathrm{A}$ and $\mathrm{Ag} \mathrm{A}$ on the erythrocyte $\rightarrow$ agglutination (nonsecretor).

\section{Statistical Analysis}

The SPSS for Windows version 19.0 software (SPSS, Chicago, Ill., USA) was used for statistical analysis. The level of significance was $\mathrm{p}<0.05$. The data were analyzed using a $\chi^{2}$ test, Fisher's exact test and logistic regression.

\section{Results}

The mean age of the patients with OLP was $51 \pm 14.6$ years, while that of the control was $50.7 \pm 13.56$ years. The demographic data and distribution of blood groups for the case and control groups are given in table 1. The distribution of blood groups of the patients was: $\mathrm{A}=7$ $(11.7 \%) ; \mathrm{B}=10(16.7 \%) ; \mathrm{O}=8(13.3 \%)$, and $\mathrm{AB}=5(8.3 \%)$. The distribution for the control group was: $\mathrm{A}=13(21.7 \%)$; $\mathrm{B}=5(8.3 \%) ; \mathrm{O}=6(10 \%)$, and $\mathrm{AB}=6(10 \%)$.

The secretor status for both groups is given in table 2 . Most subjects in both groups were secretors [ $\mathrm{n}=49$ $(81.7 \%)]$. In the case group, $25(84.4 \%)$ were secretors while $5(16.6 \%)$ were nonsecretors. In the control group, $24(80.0 \%)$ were secretors while $6(20.0 \%)$ were nonsecretors. There was no significant difference between groups concerning secretor status $(\mathrm{p}=0.73)$.

\section{Discussion}

The findings of this investigation showed that the secretor status from the saliva of patients with OLP was the same as the status of that of the control subjects. Previous 
Table 1. Demographic data and distribution of blood groups among cases and controls

\begin{tabular}{|c|c|c|c|c|c|c|c|}
\hline \multirow[t]{2}{*}{ Group } & \multirow{2}{*}{$\begin{array}{l}\text { Mean age } \\
\pm \mathrm{SD} \text {, years }\end{array}$} & \multicolumn{2}{|c|}{ Sex, n (\%) } & \multicolumn{4}{|c|}{ Blood group, n (\%) } \\
\hline & & male & female & A & B & $\mathrm{O}$ & $\mathrm{AB}$ \\
\hline Case $(n=30)$ & $51 \pm 14.16$ & $8(13.3)$ & $22(36.7)$ & $7(11.7)$ & $10(16.7)$ & $8(13.3)$ & $5(8.3)$ \\
\hline Control $(n=30)$ & $50.7 \pm 13.56$ & $5(8.3)$ & $25(41.7)$ & $13(21.7)$ & $5(8.3)$ & $6(10)$ & $6(10)$ \\
\hline
\end{tabular}

research on the etiology and pathogenesis of certain diseases has shown that the secretor status of a patient could be a factor influencing the development of systemic oral disease [4-11]. Some studies suggest that the inability to secrete blood group antigens into the saliva could be regarded as a risk factor for the development and progression of epithelial dysplasia and the development of malignant oral tumors $[4,8]$. The objective of this study was to assay this hypothesis since OLP is a precancerous condition of the oral cavity.

Cerović et al. [16] evaluated the presence of $\mathrm{ABO}$ antigens of blood types in the saliva of patients with oral cancer. Like our study, they did not find any correlation between secretor status and development of oral cancer. Lamey et al. [17] also did not record any significant differences in the distribution of secretors or nonsecretors between the patient and control groups. In contrast to our study, Hallikeri et al. [8] compared salivary secretor status in (1) patients with oral submucous fibrosis who use tobacco, (2) those who use tobacco but do not have oral submucous fibrosis lesions, and (3) healthy controls. Their results showed that all patients in group 1 were nonsecretors, $84.8 \%$ in group 2 were nonsecretors, and $15.2 \%$ in group 3 were nonsecretors. Statistically significant differences were observed between group 1 and groups 2 and 3, and Vidas et al. [4] found a higher intensity of oral disease in the nonsecretor patients and the occurrence of epithelial dysplasia in the nonsecretor group.

Thom et al. [12] has also reported that oral carriers of Candida albicans are predominantly in nonsecretors. Tabasum and Nayak [11] studied the salivary blood group antigens and their effect on the adherence of certain selected microorganisms in the oral cavity. They compared the clinical scores, secretor status, and the presence or absence of selected microorganisms in unstimulated whole saliva and subgingival plaque between patients with healthy gums, chronic gingivitis, and chronic periodontitis, and showed that there were more secretors among healthy subjects and nonsecretors were found more in the chronic periodontitis group. The clinical scores were
Table 2. Secretory status of blood group antigens in the cases and controls

\begin{tabular}{lll}
\hline \multirow{2}{*}{ Group } & \multicolumn{2}{l}{ Secretor status, } \\
\cline { 2 - 3 } & secretor & nonsecretor \\
\hline Case $(\mathrm{n}=30)$ & $25(84.4)$ & $5(16.5)$ \\
Control $(\mathrm{n}=30)$ & $24(80.0)$ & $6(20.0)$ \\
\hline
\end{tabular}

higher in nonsecretors compared to secretors in all three groups. Prevotella intermedia and Porphyromonas gingivalis were prevalent among nonsecretors in the chronic gingivitis group and chronic periodontitis patients [11].

There are some studies about the higher dental caries incidences between nonsecretor patients. Kárpáti et al. [10], showed that in mixed dentition, the mean dmf-t values were significantly lower in the secretor group as compared to the nonsecretor group. Arneberg et al. [18] also found lower dental caries in the secretors of blood group substance.

\section{Conclusion}

In this study, secretor status was neither a risk factor nor a protective for the development of OLP.

\section{Acknowledgments}

This study was based on an undergraduate thesis. The authors wish to thank the Research Center of Shahid Beheshti University of Medical Sciences, Dermatology Department in Shohada Hospital, Tehran, Iran, for their beneficial support and Dr. Fateme Mashhadi Abbas for assessment of biopsied specimens.

\section{Disclosure Statement}

The authors report no conflicts of interest. 


\section{References}

1 Schiff F: Racial differences in frequency of the 'secreting factor'. Am J Phys Anthropol 1940; 27:255-262.

$>2$ Lindqvist L: Determination of salivary $\mathrm{ABH}$ blood group antigens by rocket affinoelectrophoresis. Vox Sang 1982;42:124-130.

$\checkmark 3$ Mortazavi H, Hajian S, Fadavi E, et al: ABO blood groups in oral cancer: a first case-control study in a defined group of Iranian patients. Asian Pac J Cancer Prev 2014;1:14151418.

4 Vidas I, Delajlija M, Temmer-Vuksan B, et al: Examining the secretor status in saliva of patients with oral pre-cancerous lesions. J Oral Rehabil 1999;26:177-182.

5 Patrick AW, Collier A: An infectious aetiology of insulin-dependent diabetes mellitus? Role of the secretor status. FEMS Microbiol Immunol 1989;1:411-416.

$\checkmark 6$ Suadicani P, Hein HO, Gyntelberg F: Genetic and life-style determinants of peptic ulcer. A study of 3,387 men aged 54 to 74 years: The Copenhagen Male Study. Scand J Gastroenterol 1999;34:12-17.
7 Kulkarni DG, Venkatesh D: Non-secretor status; a predisposing factor for vaginal candidiasis. Indian J Physiol Pharmacol 2004;48: 225-229.

8 Hallikeri K, Udupa R, Guttal K, et al: Analysis of salivary secretor status in patients with oral submucous fibrosis: a case-control study. J Investig Clin Dent 2015;6:261-266.

-9 Holbrook WP, Blackwell CC: Secretor status and dental caries in Iceland. FEMS Microbiol Immunol 1989;1:397-399.

10 Kárpáti K, Braunitzer G, Toldi J, et al: Caries and $\mathrm{ABO}$ secretor status in a Hungarian population of children and adolescents: an exploratory study. Caries Res 2014;48:179-185

11 Tabasum ST, Nayak RP: Salivary blood group antigens and microbial flora. Int J Dent Hyg 2011;9:117-121.

-12 Thom SM, Blackwell CC, MacCallum CJ, et al: Nonsecretion of blood group antigens and susceptibility to infection by Candida species. FEMS Microbiol Immunol 1989;1:401-405.

13 Shin ES, Chung SC, Kim YK, et al: The relationship between oral Candida carriage and the secretor status of blood group antigens in saliva. Oral Surg Oral Med Oral Pathol Oral Radiol Endod 2003;96:48-53.
14 Mravak-Stipetić M, Lončar-Brzak B, BakaleHodak I, et al: Clinic pathologic correlation of oral lichen planus and oral lichenoid lesions: a preliminary study. ScientificWorldJournal 2014;2014:746874.

15 Navazesh M; ADA Council on Scientific Affairs and Division of Science: How can oral health care providers determine if patients have dry mouth? J Am Dent Assoc 2003;134: 613-620.

16 Cerović R, Juretić M, Balen S, et al: Examining the presence of $\mathrm{ABO}(\mathrm{H})$ antigens of blood types in the saliva of patients with oral cancer. Coll Antropol 2008;32:509-512.

$>17$ Lamey PJ, Darwazeh AM, Muirhead J, et al: Chronic hyperplastic candidosis and secretor status. J Oral Pathol Med 1991;20:64-67.

18 Arneberg P, Kornstad L, Nordbö H, et al: Less dental caries among secretors than among non-secretors of blood group substance. Scand J Dent Res 1976;84:362-366. 